ISSN: 1130-3743 - e-ISSN: 2386-5660

DOI: http://dx.doi.org/10.14201/teoredu2016282139162

\title{
PEDAGOGÍA DEL CUERPO Y ACOMPAÑAMIENTO, UNA COMBINACIÓN AL SERVICIO DE LOS RETOS DE LA EDUCACIÓN
}

\author{
Pedagogy and accompaniment, at the service \\ of education challenges
}

\section{Une pédagogie du corps et d'accompagnement, d'une combinaison au service des défis de l'éducation}

Marc Pallarès Piquer*, Joan Traver* y Jordi Planella**

* Universidad Jaume I de Castellón. Facultad de Ciencias de la Educación. Departamento de Teoría e Historia de la Educación.

Av. de Vicent Sos Baynat, s/n. 1207 Castellón.

pallarem@edu.uji.es; jtraver@edu.uji.es

* Universitat Oberta de Catalunya. Departamento de Pedagogía Social.

Rambla de Poble Nou, 156.08018 Barcelona.jplanella@uoc.edu

Fecha de recepción: enero de 2016

Fecha de aceptación: marzo de 2016

RESUMEN

El artículo se ocupa de la pedagogía del cuerpo y de la relación ética conocida como acompañamiento. Se presentan como elementos de la práctica educativa con el objetivo de determinar una visión crítica que sirva al pedagogo/a para analizar sus métodos y sus actos de intervención. Se llega a la conclusión de que se hace necesario ubicar a la Pedagogía en una intersección doblemente mediada: mediada con el cuerpo, como ámbito de educación que construye, y mediada por el acompañamiento, para que pueda devenir un elemento de intervención. Esta doble mediación habilita a la Pedagogía para desarrollar competencias adecuadas y la dota de 
un conocimiento de la educación que le permite fijar principios de intervención al servicio del dominio de la acción y, por consiguiente, le proporciona mecanismos para afrontar desafíos epistemológicos que minimicen la desconfianza creada en los últimos tiempos.

Palabras clave: educación; pedagogía; filosofía de la educación; ética; acompañamiento.

\section{SUMMARY}

This article deals with the pedagogy of the body and the ethical relationship known as accompaniment. These are presented as elements of the educational practice with the aim of effecting a critical vision which helps the pedagogues analize their methods and their interventions. We come to the conclusion that it is necessary to place Pedagogy at an intersection doubly mediated: mediated by the body, as domain of education that creates, and mediated by the accompaniment, so that it can become an element of intervention. This double mediation enables Pedagogy to develop adecuate competences and equips it with a knowledge of education which entitles it to establish principles of intervention at the service of action and, therefore, provides it with mechanisms to face up to epistemic challenges that minimize the reservations raised in the latest years.

Key words: education; pedagogy; philosophy of education; ethics; accompaniment.

\section{SOMMAIRE}

L'article s'occupe de la pédagogie du corps et de la relation éthique connue comme accompagnement. Ils se présentent comme éléments de la pratique éducative avec l'objectif de déterminer une vision critique qui sert au pedagogo/-a à analyser ses méthodes et ses actes d'intervention. Il se rend à la conclusion de ce qu'il devient nécessaire de se trouver à la Pédagogie dans une intersection doublement à moitié pleine, à moitié vide: arrivée à la moitié avec le corps, comme le domaine de l'éducation qu'il construit, et arrivée à la moitié par l'accompagnement, pour qu'il puisse devenir un élément d'intervention. Cette double médiation habilite à la Pédagogie pour développer des compétences adéquates et la dote d'une connaissance de l'éducation qui lui permet de fixer des principes d'intervention au service du domaine de l'action et, par conséquent, elle lui fournit des mécanismes.

Mots clés: éducation; pédagogie; philosophie de l'éducation; éthique; accompagnement. 


\section{INTRODUCCIÓN}

Hannah Arendt afirmaba que «lo novedoso y revolucionario en educación consiste en su carácter conservador, entendiendo por ello tanto la custodia de un patrimonio cultural y político como el suministro de herramientas que permitan al niño incorporarse debidamente a él» (Sánchez Madrid, 2011, 80-81). Vygotsky, por su parte, puso de relieve que el aprendizaje humano es la unificación creativa de la cultura y la conciencia, y resaltó que «los niños no son agentes solitarios conquistando el mundo por su cuenta. La conciencia humana necesita para su formación, por un lado, de la mediación de símbolos e instrumentos culturales y, por otro, de la mediación de otras conciencias"(Alonso, 2001, 4).

Algunos de los conceptos que, en contextos y momentos diferentes, vinculan

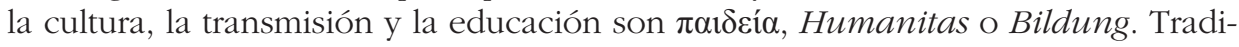
ciones griega, latina y germánica especialmente desarrolladas posteriormente por movimientos como el romanticismo alemán -con la gran tradición de la Bildungsroman ${ }^{1}$ pero también por filósofos como Gadamer. Y, en medio de todos estos contextos sociohistóricos, ha habido que integrar a la Pedagogía, "cuyo camino siempre es largo" (McCourt, 2010, 85), porque debe servir tanto para describir la complejidad de los problemas educativos de cada momento histórico como para proponer otras condiciones de vida (así como las consiguientes maneras que nos servirán para adaptarnos a ellas).

Durante el siglo xx la Pedagogía tuvo que asumir la intersubjetividad como el campo en el que se desarrollan las relaciones mediante las cuales "terminamos de hacernos en la cultura, antes o por delante de las escuelas y de los mastodónticos sistemas de enseñanza, por eso parece lógico pensar que el aprendizaje y los contenidos [...] no tienen por norte ni el desarrollo tecnológico ni la organización sociopolítica, sino que el polo está en la identidad y en la sostenibilidad de la identidad humana" (Wenger, 2001, 65), esto es, en saber quién somos, quién nos acompaña y en intentar llevar de la mejor manera posible el hecho de poder y tener que (con)vivir con el resto de personas, en definitiva.

Precisamente por ello, los sistemas educativos, reservados para las élites en otros tiempos, durante el siglo xx se vieron obligados a reestructurar sus objetivos y sus acciones, "y la comunidad educativa vino a ser llamada hacia proyectos educativos sin límite de tiempo y espacio, que apostaran por reinventarse en cada esquina” (Laudo y Prats, 2013, 259).

Esto implicó que el saber fuera abandonando su papel como eje de concentración de conocimientos para pasar a ser una posición² (Rancière, 2010). De

1. El término alemán bildungsroman se aplica a una clase de novelas en las que se muestra el desarrollo físico, psicológico o social de un personaje, habitualmente desde la infancia hasta la madurez. La palabra alemana podría ser traducida como novela de formación o novela de aprendizaje, incluso como novela de autoformación (López GALLEGo, 2013).

2. Para Rancière, "lo decisivo no está en el saber del enseñante, entendido como un cuerpo de información supuestamente disponible para ser comunicado de un lugar a otro. Lo decisivo está en otro 
hecho, el término saber fue dejando paso al de conocimiento, que últimamente ha empezado a cuestionarse, porque lo que prima son las competencias: el amor, el saber, la studiositas $^{3}$ van superándose, de la misma manera que los modelos que en la universidad tenían relación con la idea de transmisión de la cultura también han ido desapareciendo; así lo asevera, reclamándolo con un cierto aire nostálgico, Derrick $(2011,67)$ «si la educación liberal debe impartir sabiduría, los verdaderos maestros deberán ser las grandes mentes de todos los tiempos, con las que los estudiantes se pondrán directamente en contacto a través de las grandes obras de todas las edades y culturas, más que a través de las interpretaciones y los comentarios».

En consecuencia, la Pedagogía se debe marcar como finalidad principal el desarrollo de tareas cuya determinación precise de competencias alcanzadas a través del conocimiento de la educación. El cometido pedagógico tiene que ser, en primer lugar, especializado, ya que «la educación no es sólo un marco de referencia, sino un ámbito de realidad con significación intrínseca en sus términos; el alumno no es simplemente un aprendiz; la enseñanza no es sólo un aprendizaje, etcétera» (Touriñán, 2014, 13). En segundo lugar, la función pedagógica también debe ser capaz de crear principios de intervención, pues el desarrollo de la acción educativa no implica solo el conocimiento de la estructura cognitiva del alumnado (y de su contexto sociocultural), sino también la instrucción de un conjunto teórico que acredite la prescripción de normas de intervención pedagógica en términos que contengan significación connatural al ámbito de la educación; así, cada uno de los componentes estructurales de la intervención debe engarzarse a fundamentos específicos de intervención.

El objetivo último de la Pedagogía debe centrarse en la creación de ámbitos de educación (Vandenberg, 2009), "porque cada área cultural tiene que ser valorada como educación y construida como ámbito de educación» (Touriñán, 2014, 14); en consecuencia, la Pedagogía se tiene que encargar de la transformación de los contenidos de las áreas culturales en ámbitos de educación ${ }^{4}$, teniendo en cuenta que:

La tarea fundamental de la reflexión sobre la educación es estar atento a todo ese recorrido de los humanos como especie dentro del mundo de la vida, recorrido

\footnotetext{
lugar: está en la manera en que el profesor se acerca a su objeto; el modo en el que se hace presente ante él y en la relación que ayuda a estructurar con y junto al alumno; en la relación de éste con ese objeto que media entre ambos" (BÁrCENA, 2012, 46).

3. El ansia por el conocimiento es inherente al ser humano. La virtud de la studiositas mide estas ganas de saber: en parte minimizando el deseo, en parte impulsándonos a conocer aquello que nos conviene saber, y a desarrollar el esfuerzo que implica. La studiositas, como virtud moral, intenta canalizar de manera virtuosa ese anhelo por conocer. De la misma manera que sucede con cualquier virtud, regula nuestras acciones en función de la razón; pero también se encarga de otorgar a la prudencia el conocimiento que precisa para poder corregir y/o guiar las acciones humanas (VÁzQUez RAMOS, 2011).

4. TouriÑán $(2014,14)$ nos recuerda que «es importante mantener esta precisión e identificación como ámbito de actuación, porque su defensa y fundamentación contribuye a formar criterio en los profesionales de la educación acerca del valor educativo de un área cultural y su posibilidad como conocimiento pedagógico. Y esto tiene sentido en términos de definición real».
} 
que empieza reproduciendo el diseño de la especie en un cuerpo que no puede sobrevivir sino incorporándose a un espacio relacional compuesto por comunidades de humanos; ahí toma modos de ser y estilos de hacer, desarrolla unas capacidades y se inhibe en otras; allí es donde construye la obra más maravillosa, compleja, exclusiva, participada, comprometida, afiliada, poliédrica, a la que todos señalamos como identidad (García Carrasco y García del Dujo, 2001, 41).

En las páginas que siguen nos vamos a ocupar de la pedagogía del cuerpo y de la relación ética (del educando con el educador) conocida como acompañamiento. La intención es presentar estos dos sustratos de la mentalidad pedagógica 5 como elementos de la práctica educativa en tanto que acción, con el objetivo de determinar una visión crítica que pueda servir al pedagogo/a para analizar sus métodos y sus actos de intervención pedagógica. Así, dotamos a la Pedagogía de un conocimiento de la educación que le permite fijar principios de intervención al servicio del dominio de la acción y, por consiguiente, le proporcionamos mecanismos para arrostrar desafíos epistemológicos que pongan remedio a la desconfianza creada en los últimos tiempos ${ }^{6}$.

\section{LA Pedagogía del CUERPo}

Hace ya casi cuatro décadas que Nassif $(1977,59)$ afirmó que «indudablemente la biología es la primera de las ciencias con las cuales se relaciona la pedagogía. No es posible pensar en la formación del hombre [...] si previamente no se conoce su estructura morfológica, su capacidad de adaptación biológica, los momentos de su desarrollo orgánico, su diversidad tipológica». Y Hubert ${ }^{7}$ expuso que el desarrollo de la pedagogía implica el conocimiento de las leyes generales de la vida, pero también el conocimiento de los condicionantes del desarrollo humano, la instrucción de las maneras que bajo el influjo de los condicionantes biológicos puede tomar nuestra estructura mental ${ }^{8} \mathrm{y}$, en última instancia, el conocimiento de la anatomía y la fisiología humanas. Sin embargo, este último aspecto ha sido uno

5. Tal y como señalan KAAGAN y HEADLEY (2010), la mentalidad pedagógica solo tiene sentido si se relaciona con la base de significación del conocimiento de la educación, porque lo que certifica el conocimiento de la educación es su capacidad para minimizar problemas.

6. Efectivamente, aspectos tales como su excesiva teorización o la desaprobación de su naturaleza normativa terminaron provocando que algunos autores considerasen a la Pedagogía como una disciplina poco útil para describir los ámbitos de realidad que se desarrollan en la educación (BREZINKA, 2002), sobre todo cuando vio cuestionada su legitimidad tras la llegada de la posmodernidad (GozÁLVEZ PÉrEz, 2010), circunstancia que, en determinados contextos, instauró una "auténtica desconfianza en los educadores acerca del valor de la Pedagogía para asumir las circunstancias educativas reales y concretas» (AYALA, 2011, 121).

7. Citado por Leithwood, Mascall y Strauss (2009).

8. Desde el punto de vista cognitivo, hay tres planteamientos que han alterado la manera como se venía interpretando la articulación de la mente humana: la psicología computacional, la cognición extendida y la cognición encarnada (HERNANDO, 2012). 
de los grandes olvidados por la Pedagogía moderna; y esto a pesar de que MerleauPonty afirmara en 1945 que "no tengo un cuerpo, sino que soy mi cuerpo" y a pesar también de que autores como Bourdieu advirtiesen que el cuerpo concurre de manera cómplice del juego social (Santos Gómez, 2013a).

Aunque «todas las corrientes pedagógicas implican una concepción del cuerpo" (Arboleda, 1997, 83), la Pedagogía no siempre ha dispuesto del soporte de las diferentes disciplinas para elaborar un concepto propio sobre el cuerpo, ni ha recurrido a corrientes pedagógicas para estructurar una concepción del cuerpo desde sus fundamentos (Synnott, 1991; Teddlie y Reynolds, 2000). Todo esto ha conducido a que

Los lineamientos definidos en las políticas educativas respecto al cuerpo constituyen una normatividad que lejos está de asumir el sentido del cuerpo; esto es, la corporeidad, como un elemento sustantivo en la formación integral de los individuos. El cuerpo ha sido limitado al campo motriz, llámese educación física, juego, teatro, recreo entre otros - de lo que se infiere que se ha descorporeizado el denominado terreno intelectual- que si bien ofrece profundas alternativas pedagógicas, no justifica la eliminación del cuerpo en otras esferas (Arboleda, 1997, 83).

En la práctica pedagógica del área de la educación física ha predominado una tendencia que solo ha tenido en cuenta proyecciones del cuerpo como meras aceptaciones de una concepción totalmente vitalista de lo físico (Nelson y GordonLarsen, 2006). Esta concepción vitalista no se ha preocupado de implantar correspondencias entre "tener un cuerpo" $\mathrm{y}$ "ser un cuerpo» (Arboleda, 1997), por eso ha terminado excluyendo del sentir pedagógico a otros elementos que conforman la esencia del ser integral.

El conocimiento de aquello relacionado con lo físico se redujo a un mero momento epistemológico: en las clases de educación física, todo pasaba por el conocer, y no tanto por el experimentar. Así, el acto de conocer algo sobre el cuerpo se restringe a un momento de la intervención, con lo que «no se produce conocimiento más que desde la mera acción, en el actuar, y nunca desde la condición de alumno-espectador» (Mondzain, 2007, 66).

Pero la Pedagogía puede asumir la necesidad de ampliar la concepción vitalista del cuerpo y promover otras ideas sobre el cuerpo, que necesitarán ser canalizadas en propuestas pedagógicas que vertebren proyectos que integren los conceptos de instrucción, formación y enseñanza-aprendizaje.

Hablamos de una pedagogía del cuerpo que tiene sentido en la medida en que se incluya dentro del proyecto personal del sujeto, y no solo en los programas institucionales que, con frecuencia, incluso predeterminan qué tipo de cuerpos quieren (Planella, 2006). Como recuerda Touraine (1997, 116), «el sujeto ya no se forma, como en el modelo clásico, asumiendo unos papeles sociales, [...] se construye imponiendo a la sociedad instrumentalizada, mercantil y técnica, unos principios

9. Citado por Planella (2006, 279). 
de organización y unos límites conformes con su deseo de libertad y su voluntad de crear unas formas de vida social favorables a la formación de uno mismo y en el reconocimiento del Otro como sujeto".

Se trata, por consiguiente, de «repensar la mirada que hacemos desde la pedagogía, sobre los cuerpos de los educandos, y analizar cómo la pedagogía educa a los sujetos pedagógicos sobre su propio cuerpo» (Planella, 2005, 190). Con esta actuación, se cumple la premisa de que hay que exigirle al binomio educaciónpedagogía que las acciones humanas de las que se ocupan se enmarquen dentro de un proyecto concreto con objetivos intencionales determinados. Es una actuación basada en la dinámica de la educación y que representa una propuesta (pedagógica) como actividad circunscrita a la construcción de una experiencia que servirá como fuente de creación de actividad educada. Al hablar de proyectar conceptos y paradigmas ${ }^{10}$ desde la propia corporeidad (y no en función de maneras y vivencias corporales que sean dadas exteriormente), hay que resaltar que «usamos la actividad para intervenir y educamos en la actividad» (Touriñán, 2014, 28).

Tal y como ya anunció Freinet (1972), más que despojar al niño o a la niña de su corporeidad, la pedagogía del cuerpo debe conectar a los educandos con ella. Demandar que se tenga en cuenta esta pedagogía es oponerse al poder que, según Vigilar y castigar (Foucault, 1976), calibra, subordina y estima los cuerpos de los educandos. Por lo tanto, del cuerpo tutelado (o incluso abolido) de Foucault pasamos a unos cuerpos capaces de expresarse, preparados para subjetivar su realidad, para transitar de su mero estado físico a su estado simbólico (Huerta y Alonso Sanz, 2015) y que nos alejan de aquellas "pedagogías que podríamos considerar como canónicas, que poco han aportado para hacernos más conscientes del mundo en que vivimos" (Ferraz, 2012, 5).

\subsection{El cuerpo como punto de inflexión hacia un proyecto de vida}

El cuerpo y nuestra propia imagen ocupan un lugar relevante en el proceso de mediación de la experiencia humana "convirtiéndose en un medio y un valor tan fuerte que se han transformado en proceso de culto, en un bien de uso y de consumo y sobre el que recaen expresiones retóricas y figurativas de la perfección y la felicidad" (Fanjul, 2006, 315). La Pedagogía del cuerpo no demanda una concepción sobre la educación que se limite a describir algún lugar (o concepto) del modo de vida del educando, sino una actuación que permita explicitar maneras de

10. Platón utilizó el término de "paradigma" para referirse a conceptos tales como "ejemplo", "modelo", "patrón" o "copia». En este artículo es usado en los términos de la epistemología, sobre todo en la noción de KuHn (1978) según la cual un paradigma se enmarca dentro del ámbito general de la ciencia y opera en marcos regidos por modelos teóricos que van acumulando el conocimiento y van solventando las indecisiones y/o dificultades que la evolución humana va presentando. Así, cuando surgen anomalías en el paradigma, se reajustan los conceptos que lo conforman. En el caso de que las anomalías sean desmesuradas, lo que se hace es poner en duda la vigencia del paradigma. 
intervención pedagógica que aseguren la potestad del educando para optar a su proyecto de vida, instruyendo a usar su experiencia como vía para afrontar muchas de las exigencias que le tocará asumir en su vida diaria. Al insertarse en una especie de actuación de «autodeterminación corporal» (Planella, 2006), en esta proposición pedagógica cada educando «está invitado a producir su propia identidad a través del bricolaje por la mundialización cultural» (Le Breton, 2002, 16).

El cuerpo es interpretado por el sujeto que lo encarna, es así como la pedagogía del cuerpo entiende que el educando es el generador de su identidad corporeizada y quien integra al cuerpo en una realización consigo mismo, "todos los elementos de la corporeidad se proyectan en la capacidad ${ }^{11}$ del sujeto de idear su corporeidad" (Planella, 2006, 286). Sin embargo, de esto no se deduce que el cuerpo se "pueda tener ${ }^{12}$ en el mismo sentido que disponemos de aptitudes concretas o de competencias de actuación (Bárcena, 2012), sino que:

Cada situación en la que actúo educacionalmente con niños requiere que yo sea sensible de un modo continuo y reflexivo a aquello que me autoriza en tanto que profesor [...] porque la pedagogía es [...] insondable y plantea una invitación incansable a la actividad creativa de la reflexión pedagógica que hace salir a la luz el significado profundo de la pedagogía (Manen, 2003, 164-165).

El hecho de rescatar al cuerpo y reclamarlo como actor de la pedagogía hace que sea necesario distinguir la comprensión de la transmisión de informaciones. La primera sitúa activamente al educando en la base de la acción; la segunda lo contextualiza como agente de recepción. Pero lo relevante es que el educando sea capaz de indagar el origen de su corporeidad en el conjunto de sus vivencias (Planella, 2006). Estamos de acuerdo con Alemany $(1996,109)$ en que la posibilidad de que se produzca esta autocomprensión «la ofrece el convencimiento de que lo auténticamente importante es vivir lo que es real y que el cuerpo tiene como propiedad justamente el riesgo inmediato de una realidad que es vivida significativamente por nuestro organismo de forma global».

Vivir de manera corporeizada es, a la postre, centrarse en la manera de entender nuestras vivencias, a las que vamos moldeando a través de unos procesos de simbolización de nuestro cuerpo que nos permiten percibir que somos alguien «singular, único, y como tal debemos saber interpretar el contexto en el cual vivimos, con su historia y tradición, para poder realizarnos» (Pagano, 2001, 48).

11. Estamos de acuerdo con la noción de capacidad que sostiene NAUSSBAum (2012): No son simples habilidades residentes en el interior de una persona, sino que incluyen también las libertades o las oportunidades creadas por la combinación entre esas facultades personales y el entorno político, social y económico. Según declara Nussbaum, la idea intuitiva básica de su enfoque de las capacidades es que debemos partir de una concepción de la dignidad del ser humano y de una vida acorde con esa dignidad. Las capacidades se entienden como requisitos mínimos básicos para una existencia digna y formarían parte de una teoría mínima de la justicia social (Guichot-ReinA, 2015, 51).

12. Hay que tener en cuenta que no "poseemos" nuestro cuerpo sino que "somos" en cuanto este cuerpo, por eso no decimos "haces daño a mi cuerpo" sino "me haces daño" (RomBach, 2004). 
Esta singularidad nos presenta la necesidad de construir un proyecto, de proponer una serie de subjetividades que tendrán su eje en la corporeidad ${ }^{13}$. Dejamos a un lado el papel que en discursos pedagógicos del pasado ${ }^{14}$ había sido reservado al cuerpo (un cuerpo que se concebía como algo sincronizado y controlado, incapaz de poder actuar de manera autónoma) y nos centramos en «repensar qué pedagogía corporal existe y cuál es el papel del cuerpo en esta praxis» (Planella, 2005, 199).

La proyección social de la educación llevada a cabo durante la mayoría de las tendencias pedagógicas de la primera mitad del pasado siglo xx no se llevó a término a expensas del individuo, se produjo con él, en relación a su comprensión y en función de su conocimiento científico (Marchart, 2009); porque la educación no es una socialización exterior sino un mecanismo (vasto y complejo) de integración del individuo en la comunidad centrado en el desarrollo pleno de lo personal. Es por ello que el cuerpo no puede quedar al margen de los planteamientos pedagógicos actuales.

La pedagogía del cuerpo se dispone en lo que Touraine (1997) llamó «Escuela del Sujeto", donde hay dos elementos fundamentales: el primero, tener presente que no tenemos un cuerpo sino que el cuerpo somos nosotros mismos. De esta manera, la pedagogía se aleja del modelo dual en el que se nos concibe como cuerpo-alma $^{15}$. El segundo, que la pedagogía de la corporeidad se desarrolle a partir de los elementos corporales, sobre todo a partir de los sentidos, por eso se debe basar en una pedagogía sensible que "permita [y obligue] a poner en circulación los sentidos de los educandos. [...] Podemos ver en este tipo de Pedagogía una Pedagogía que se abre a las posibilidades del cuerpo pero que a la vez busca

13. Nótese que, en esta concepción, subyace un cierta positividad, que contrasta con el lastre que acompaña a la historia del cuerpo: el cuerpo es una cárcel para el alma (Platón); el cuerpo nos impide acceder al conocimiento (Descartes); el cuerpo es uno de los gérmenes del pecado (cristianismo) (Planella, 2006).

14. Sobre la función que ha desempeñado el cuerpo en la historia de Occidente AGUiRRE (1993, 146) asegura que "no se puede entender el concepto de cuerpo sin aludir a las grandes corrientes filosófico-teológicas que actúan en la cultura occidental como sustrato conceptual de referencia». Ha habido multitud de enfoques sobre el binomio cuerpo-alma, que no han transcurrido de manera lineal y que se han localizado en contextos diferentes. A partir de las aportaciones de la Antropología cultural, las ciencias sociales han contado con registros lingüísticos que han facilitado la reconstrucción de la historia del cuerpo, hecho que lleva a PORTER $(1993,258)$ a constatar que «sería [...] simplista suponer al cuerpo humano una existencia intemporal como objeto natural y no problemático, con necesidades y deseos universales».

15. Hay distintas maneras semánticas de interpretar el cuerpo: entendido como elemento antagónico al alma (antropología dualista), interpretado como la parte física de la persona, es decir, limitando el cuerpo a lo anatómico (materialismo) o concibiendo al cuerpo como sinónimo de la persona, como se hace desde este artículo. Partimos, por consiguiente, de una visión integral del sujeto próxima a la concepción unitaria del mismo, alejada de las concepciones dualistas. Esto quiere decir que cuando anunciamos el término cuerpo no estamos situando solo la materialidad, lo físico, sino que, en el sentido más merleau-pontiano, hablamos de cuerpo vivido, encarnado, habitado. 
despertar al educando, no dejarlo dormido, darle la palabra y, en cierta forma, permitirle circular» (Planella, 2016, 2).

Disponemos de pocos autores e investigaciones sobre la teoría del cuerpo elaborada desde la pedagogía. Fullat (1989) reclamó a finales de los 80 la necesidad de tener presente, en el pensamiento pedagógico, la diferencia entre el cuerpo-objeto y el cuerpo-propio: "Educar la conciencia corporal o cuerpo-propio, en el sentido de avivarla y animarla, y no en el sentido de manufacturarla o confeccionarla» (Fullat, 1989, 164).

Bárcena y Mèlich (2000) analizaron las relaciones entre el cuerpo y la educación como fuente de sentido, y no solo en cuanto a su mera materialidad fisica. Y en 2002, en Le parole del corpo, Fullat defendió abiertamente que el cuerpo-propio es un elemento que se erige en nuestra propia existencia; de alguna manera, Fullat sentó las bases que permitieron a Vilanou (2002) plantear una hermenéutica pedagógica del cuerpo a través de la cual se perciba al cuerpo desde la construcción social que se realiza en los cuerpos de los educandos.

En lo que se refiere a la perspectiva social y cultural del cuerpo, Vilanou se postula a favor de un paradigma que desarrolle un modelo hermenéutico a partir del cual interpretar y reestructurar nuestras realidades; nos ubica en una práctica de reformulación del cuerpo que tenga como objetivo "reconfigurar un universo simbólico y relacional en torno al cuerpo humano que, en lugar de ser dominado, segregado o colonializado, pueda despertar la conciencia de una nueva realidad social e individual" (Vilanou, 2001, 95). Por todo ello podemos afirmar que no se debe aceptar el cuerpo como una simple estructura biológica sino que tiene que «convertirse en $m i$ cuerpo mediante una tarea que dure toda la vida» (Rombach, 2004, 295).

\subsection{Los cuerpos en la era de la tecnologización}

A pesar de ciertas reticencias $^{16}$, en las dos últimas décadas ${ }^{17}$ el cuerpo ha dejado de ser un elemento exclusivo de disciplinas como la antropología ${ }^{18}$ y la

16. En palabras de $\operatorname{SENNETT}(1997,17)$, «a la civilización occidental le resulta difícil honrar la dignidad del cuerpo y la diversidad de los cuerpos humanos".

17. Fue a finales del siglo xx e inicios del siglo XXI cuando se asentaron las dos concepciones sobre el cuerpo: una primera (cuerpo-objeto-orgánico) más husserliana, que entiende que el cuerpo es algo modelado según aquello que la sociedad espera de él; y una segunda concepción más subjetiva (cuerpo-sujeto-intencional), que es aquella que entiende que el cuerpo no está terminado, por eso todos podemos «añadirle nuestra propia marca, nuestro propio signo de identidad» (LE BRETON, 2002, 31).

18. Aunque queda fuera de los objetivos de este artículo, quisiéramos poner en valor la antropología de la substancia de Rombach, puesto que su definición nos sitúa en un campo en el que las fronteras entre la antropología y la pedagogía se reducirían al máximo, pues la antropología de la substancia «supone un núcleo esencial en el individuo que se encuentra bajo las determinaciones individuales, cambiantes y casuales; un núcleo que las sostiene, las une y les da sentido y consistencia. El modelo de la substancia subraya que hay "algo" en el hombre, "algo" universal e inmutable, que se establece en todos los seres humanos de la misma manera y solamente se manifiesta como un principio 
sociología, puesto que se ha comenzado a aceptar que el cuerpo puede tomar la palabra del sujeto y está habilitado para emitir significados, "no se trata sólo de lucir la anatomía corporal, sino de dejar aflorar los símbolos que los cuerpos llegan a transmitir» (Planella, 2005, 193). Además, la inserción de la imagen del cuerpo en las nuevas tecnologías ha abierto el camino del "tercer entorno" (Echeverría, 2003), que ha permitido que, a partir de la expansión de Internet y del uso masivo de las redes sociales, "el enfoque tecnocultural de la cibernética supere los estrictos límites de la ciencia afectando, también, aspectos antropológicos más allá incluso de la articulación de un incipiente homo digitalis» (Vilanou, 2003, 359). Todos los avances de la era tecnodigital permiten incluso la aparición de nuevos discursos corporales, más volátiles (Veletsianos, 2010), y hacen que moverse por el ciberespacio sea sencillo, lo que "supone cambiar algunos aspectos claves de la existencia que han caracterizado a los cuerpos hasta la actualidad. Los sujetos con discapacidad pueden desplazarse por el ciberespacio sin dificultades, con menos barreras culturales, sociales y mentales» (Planella, 2006, 33).

A la múltiple cantidad de imágenes ${ }^{19}$ que nos proporcionan las redes les corresponde una redistribución de las clásicas maneras de espectatorialidad; al concentrarse todo en un solo público performer (Mattei, 2014), es más complejo diferenciar entre un espacio de observación y un espacio performativo. Como afirma Shirhy (2011), las redes sociales tienden a influenciar a las personas como lo hacían el cine y las telenovelas antaño; y Facebook e Instagram colocan a los cuerpos de personas famosas cerca de nosotros, cosa que en el pasado no era posible.

Sin embargo, aunque la posibilidad de tener cuerpos humanos esté a un solo click, «el cuerpo del actor no es un actor, sino un actante» (Orlan, 2002, 203), esto es, se trata de cuerpos que, navegando por la esfera tecnodigital, adoptan dimensiones proyectivas que solo nos afectan en la medida en que nos permiten (re)construir nuestra idea del cuerpo. Nada más. Es únicamente «nuestro» cuerpo (tangible) aquel que puede decir algo sobre lo que las cosas y los hechos son, cómo y por qué son. También será nuestro cuerpo quien podrá manifestar cómo se puede actuar y cuáles son estas maneras de actuar como ser humano en las que «se reafirma su humanidad, así como los modos que por el contrario la desmienten. En definitiva, qué es lo que realmente nos ayuda a crecer como personas» (Barrio Maestre, 2008, 537).

Los cuerpos que ocupan las pantallas de la era digital quizá avancen la configuración de la vertiente subjetiva relacionada con la dimensión pedagógica y corporal del futuro, en una intersección en la que el nexo "conocer-saber-deseo" tal vez se decantará hacia una construcción binaria que, en las sociedades que

de unidad encubierto por la diversidad de la sensibilidad y la abundancia de transformaciones» (RomBACH, 2004, 27).

19. A este respecto resulta evidente que la tecnología ha transformado aspectos como la fotografía: en la era digital, el poder de la imagen se ha multiplicado de manera exponencial hasta el punto de reafirmar su omnipresencia (PÉREz DAZA, 2015), ya que "prevalece la circulación y gestión de la imagen sobre el contenido de la imagen" (FonTCUBERTA, 2011, 3). 
están por llegar, podría remitirnos a un campo ubicado entre la objetividad y la subjetividad (Herrera y Codina, 2015); pero la formación de un sujeto pedagógico ${ }^{20}$ inserto en una pantalla todavía forma parte de la utopía pedagógica, porque la creación del binomio «objeto pedagógico-sujeto pedagógico» necesita (aún) de enfoques antropocéntricos, por lo menos mientras el ser humano siga siendo el actor preponderante en la formación de individuos y subjetividades. En este sentido, Bernasconi $(2015,224)$ afirma que:

Los estudios sociales de individuos y subjetividades tienden a concentrarse en dos
procesos: la producción o fabricación del individuo (por las estructuras) y las for-
mas de comprensión, experimentación y reflexión que hacen las personas de su
individualidad -la autointerpretación (el nivel micro o subjetivo)-. Una aproxima-
ción post-humana, relacional y pragmática permite acceder al estudio de procesos
complementarios. Esto habilita para investigar la multiplicidad de formas en que
un individuo es traído a existencia y, seguidamente, indagar en los procesos de
movilización, distribución y transformación de individuos en y por lo social.

La pedagogía del cuerpo solo es posible en la medida en que los individuos existen, forman parte de prácticas socioeducativas concretas en las que «se produce una tensión entre el deseo de aprender del cuerpo-sujeto-pedagógico y el cuerposujeto-docente» (Planella, 2006, 262).

Relacionamos e integramos la pedagogía del cuerpo con el desarrollo positivo humano, aquel que "requiere retomar en educación esta dimensión -cuidado de sí- en el sentido de dotar al propio sujeto de las cualidades y disposiciones del carácter, además de habilidades intra e interpersonales que le lleven a liderar su propio proyecto vital» (Romero Pérez y Pereira, 2011, 75). Y añaden que «la educación positiva, en este sentido, propone una visión integradora de la formación de la personalidad a través de la educación emocional y la educación del carácter».

Con la pretensión de completar el concepto de realización del pleno potencial humano aristotélico (felicidad-vida buena-crecimiento personal), demandamos que en él se tenga también en cuenta al cuerpo. Frente al concepto de bienestar hedónico, planteamos una ampliación de la visión eudemónica, pues agregamos al constructo del bienestar social y psicológico la concreción de una pedagogía del cuerpo que permita la existencia de sujetos corporeizados como vía para intentar alcanzar la plena realización del potencial educativo al que toda sociedad pretende aspirar.

La educación es un curso histórico-social perenne, incompleto y mediatizado por el medio en que se produce, por eso el acto educativo deviene a la vez un

20. Además de lo expuesto, también hay que descartar que la imagen-cuerpo que aparece en las redes sociales sea capaz de convertirse en sujeto corporeizado porque «son más una caja de resonancia de discursos ya constituidos e instituidos, un espacio que se limita a permitir la ampliación y la modulación (bastante desordenada) de determinadas ideas que ya se encuentran circulando en diferentes ámbitos de la sociedad, antes que un nuevo lugar de participación plena tendiente a la creación de un colectivo que pueda constituirse en un actor social de importancia» (RAImONDO, REviglio y Divani, 2015, 12). 
proceso de socialización y de individuación, donde, para que surja el aprendizaje del educando, se precisa de un tipo especial de docente, "el maestro de sentido, capaz de conectar con la mente del que aprende, respetar sus intereses y posibilidades para integrarle en el medio que le rodea de una forma individual y crítica» (Le Breton, 2000, 35), alguien que le acompañe, en definitiva, ya que:

El educador debe ante todo desarrollar un estar en sintonía, un «talante» o «tacto» pedagógicos, no tanto como empleo de métodos a priori o de técnicas dialécticas, sino como diálogo con el educando y el medio común (cultura, historia), que arranque siempre a posteriori, tras la inmersión de la práctica (Santos Gómez, 2013b, 3).

\section{HACIA UNA NUEVA PAIDEIA ${ }^{21}$ BASADA EN EL ACOMPAÑAMIENTO}

Como indica Ortega Ruiz (2004), durante la segunda mitad del siglo XX se estudiaron con detenimiento los condicionantes que repercutían en los procesos de enseñanza-aprendizaje, pero se analizó menos la relación del educador con el educando.

El educador tiene el deber ético de actuar como sujeto responsable, preparado para autoexigirse la responsabilidad del acto educativo en un intento de dar voz a la actuación (al acto educativo mismo) y a la reciprocidad. El hecho de que el educador tenga este deber ético no implica que la ética devenga el objetivo último de la educación, ni una competencia que se deba lograr, la ética debe limitarse a

... la condición de posibilidad de la relación educativa. La ética es una de las formas que adopta la excentridad humana. Por eso no hay educación sin ética. La "moral", todo el conjunto de valores, normas y hábitos en los que un ser humano ha sido formado, forma parte de la cultura y, por lo tanto, de la naturaleza humana, del "mundo". La "ética», en cambio, surge al "poner en cuestión» la naturaleza. Hay ética si soy capaz de "problematizar» mi propia naturaleza (biológica y cultural), si existe la posibilidad de entrar en crisis. La ética no forma parte de la naturaleza sino del hiato entre la naturaleza y la condición humana, entre el «mundo» y la «vida» (Mèlich, 2008, 122).

Además, en el desarrollo de la práctica docente y en el fomento de la reciprocidad de la relación educativa no se debe negar la individualidad ${ }^{22}$; por el contrario,

21. Utilizar la etiqueta de "nueva paideia» no tiene otra pretensión que abrir una vía para percibir la educación como acción humana a favor de la socialización intencional y como práctica prohumanista dentro del actual sistema de creencias e ideologías dominantes (FERRAz, 2012). Así, lejos de pretender promover un ideal regulativo que tenga que fijarse institucionalmente, presentamos, de forma modesta, una propuesta para que vaya incardinándose en el sentir de la Pedagogía, a quien se habilita tanto para comprender el concepto de educación (en general) como para determinar los elementos que condicionan y establecen su significado frente a cualquier otra manera de interacción.

22. Afirma Veletsianos $(2010,19)$ que «la individualidad del educando tiene que ser el punto de inflexión a partir del cual el docente le ayude en la formación de su personalidad. Quien educa, pues, 
de lo que se trata es de enriquecerla y habilitarla para que, como una práctica de la conciencia, sea una vía para fortalecer el hecho educativo.

La educación es una herramienta cuyas disposiciones antropológico-políticas actualmente se ven supeditadas con mucha frecuencia a las condiciones de su implementación (que luego son evaluadas por indicadores como los informes PISA, etc.) y a la capacidad para generar confianza. De esta manera, no hay análisis epistemológico que pueda determinar el concepto de pedagogía si no da cuenta de la autonomía de lo pedagógico frente a otros ámbitos del saber y del hacer humanos que superen la anacrónica perspectiva lógico-racional basada (exclusivamente) en la capacidad de conocer la verdad y en la facultad de medir lo real (López Herrerías, 2010). En este sentido, De Miguel Díaz (2015, 281) asegura que «a lo largo de las últimas décadas se han utilizado diversos "argumentarios lógicos" como criterios de racionalidad científica para avalar los "conocimientos" obtenidos en los trabajos de pedagogía empírica».

La solidez de un sistema educativo se pone de relieve cuando el conjunto de sectores sociales preocupados por su funcionamiento consiguen que la sociología y la pedagogía dejen a un lado su rol de evidencia para pasar a potenciar una mirada (Pallarès Piquer, 2014), es decir, la fijación de un espacio crítico pero que, a la vez, entienda que «la relación previa a todo estudio teórico emprendido por la pedagogía, entendida como ciencia o reflexión que se establece con los niños, es una relación de cuidado, de acogida, de receptividad" (Santos Gómez, 2013b, 3).

Este cuidado permite que el niño o la niña se abran al mundo del sentido y de las sensaciones, aprendan con todo su cuerpo, realicen el aprendizaje de la libertad, descubran su capacidad para crear los límites del mundo en el cual anhelan vivir de la manera más feliz posible, en definitiva; todo ello sin olvidar que «la condición del hombre sigue siendo el inacabamiento, una aptitud infinita de conectarse en cada momento al mundo. La más bella adquisición del niño no es la de almacenar conocimiento, sino la de no ignorar que el mundo jamás le será dado en su totalidad, y que no acabará nunca de aprender» (Le Breton, 2000, 42). Por eso algunos afirman que "de hecho, la pedagogía sería más útil si no se centrara tanto en ofrecer respuestas, sino en interrogar(se), en sospechar de sus propias explicaciones y en introducir elementos marginales en su discurso» (Santos Gómez, 2013b).

Durante las últimas décadas, este acto de ofrecer respuestas al que alude Santos Gómez (el aprender) se ha planificado (e incluso se ha subordinado) desde los parámetros de la eficacia (Ainscow, Hopkins, Soutwort y West, 2001). Las teorías pedagógicas más influyentes introdujeron la dimensión temporal, esto es, se centraron en el proceso de formación de la persona (Alonso, 2001), pero siempre a partir de las oscilaciones que operaban sobre los procesos de enseñanzaaprendizaje, como si el único objetivo de la pedagogía fuese constatar aquello que sucedía en las aulas.

debe empezar por conocer la individualidad de quien es educado, su naturaleza, su manera de ser y sus posibilidades". 
Pero «esta preocupación por la eficacia [...] no ha dado lugar, en la misma medida, a una enseñanza mejor en todas las dimensiones de la persona. Una pedagogía más racional y científica no ha dado paso a una pedagogía con rostro humano»33 (Ortega Ruiz, 2004, 6). La época del análisis, de la especulación y del esencialismo pedagógico ya no tiene sentido, y no solo desde un enfoque basado en la esterilidad de la eficacia, sino desde una planteamiento de cambio social, de cambio socioeducativo centrado en evidencias (March, Orte y Ballester, 2016).

Este camino repleto de desaciertos, que ha llevado a la Pedagogía a obsesionarse con la eficacia, ha consistido en ignorar que el deber ético y la intención pedagógica no se pueden aislar (Kristal, 2002), porque «educar es y supone algo más que la simple implementación de estrategias o conducción de procesos de aprendizaje. [...] En la relación educativa el primer movimiento que se da es el de acogida, de la aceptación de la persona del otro en su realidad concreta, en su tradición y cultura, no del individuo abstracto» (Ortega Ruiz, 2004, 9).

\subsection{La educación como experiencia ética}

Por encima de ser un mero acontecimiento, la educación, en sí misma, es una experiencia ética (Buzzelli y Johnson, 2002) que nos demanda salir de nosotros mismos, "hacerlo desde el otro lado, cruzando la frontera" (Bárcena y Mèlich, 2003, 210), pues educar implica ver el mundo desde la pluralidad, desde la experiencia de los otros ${ }^{24}$, y esta relación ética es:

La que hay que salvar, si se quiere educar y no hacer "otra cosa». Pocas veces los educadores y pedagogos nos damos verdadera cuenta de lo que es y supone situarse ante un educando como alguien que demanda ser reconocido como tal. Educar nos obliga a negar cualquier forma de poder, porque el otro (el educando) nunca puede ser objeto de dominio, de posesión o de conquista intelectual. En segundo lugar, exige la respuesta responsable, es decir, ética a la presencia del otro (Romero Sánchez y Pérez Morales, 2013, 105).

La pluralidad de situaciones establece una pluralidad de yos, y el yo se instituye y se experimenta como una secuencia multidimensional. Por eso no hay acontecimiento educativo si no hay situación: "No me puedo concebir de ningún otro modo, no puedo alcanzarme a mí mismo si no es a través de la situación. Nada llega a mí sino a través de la situación» (Rombach, 2004, 141).

23. El propio ORTEga Ruiz $(2004,5)$ afirma que «la relación más radical y originaria que se establece entre maestro y alumno, en una situación educativa, es una relación ética que se traduce en una actitud de acogida, y un compromiso con el educando, es decir, hacerse cargo de él».

24. Siguiendo a Lévinas, admitir a los otros en el proceso de enseñanza es aceptar todo lo que nos trasciende y nos desborda, lo que va más allá de la capacidad de nuestro yo y nos obliga a salir de él (BÁrCENA y MèLICH, 2003). 
La situación es la estructura básica de la existencia; y la situación es lo que nos afecta desde el inicio, es lo que nos instruye y nos cambia. "La situación se puede definir justamente como mi afectación, por eso es necesario insistir en el hecho de que no hay yo, no hay identidad humana sin situación, sin una situación» (Mèlich, 2008, 117).

En unos momentos como los actuales, cuando los cambios estructurales que los medios infocomunicacionales han introducido en nuestra manera de adquirir, procesar y utilizar la información (insertos en una cultura que depende cada vez más de la imagen y de la simultaneidad) han impulsado la incursión de procesos de pensamiento diferentes a los que tradicionalmente venían operando (Hernando, 2012), la educación requiere de una nueva paideia. Ya no es razonable continuar aceptando el pensamiento hipotético deductivo y lógico conceptual como aquel que valida a la ciencia y que describe la etapa final del desarrollo intelectual, como se venía haciendo desde Aristóteles.

Por el contrario, se puede afirmar que, en el mundo actual, se hace complejo establecer las causas específicas del desarrollo cognitivo, puesto que éste «depende más de la variabilidad y, por lo tanto, no hay un plan preestablecido ni una direccionalidad única sino la posibilidad de trayectorias evolutivas infinitas que, de acuerdo con las historias particulares de interacción, harán que se tomen rumbos particulares y que, en algunos momentos, converjan con las trayectorias de la mayoría» (Garavito y Yáñez, 2009, 66).

Esta nueva paideia exige un paradigma pedagógico en el que el educador debe conocer los procesos que regulan la formación y estructuración de las representaciones, las de su yo y las del yo de su alumnado, actuando y participando en los mecanismos de reestructuración de cada perspectiva. El educador, en cierta manera, no puede rehuir la asimetría implícita en la situación de la educación: el suyo es un rol puesto al servicio del yo del alumnado, al que debe acoger y acompañar, un papel que se relaciona con situación y con la realidad in fieri del educando.

La reconstrucción de la asimetría conlleva una vía de crecimiento centrada en la colaboración, que proviene de un acuerdo de formación que tiene como base no solo la confianza, sino también el sentido de la responsabilidad y, sobre todo, el acompañamiento. No hablamos de la noción de acompañamiento como forma de conexión entre la diversidad funcional y la pedagogía social, aquella que apuesta por el acompañamiento como propuesta de trabajo con dicho colectivo ${ }^{25}$, sino del acompañamiento como proposición pedagógica «que es una teoría y una práctica que cree que educar está más cerca del tacto ${ }^{26}$ que de la táctica» (Mèlich,

25. Aplicado a esta situación, Planella $(2013,123)$ afirma que «el término acompañamiento es en realidad un concepto paraguas o un concepto esponja, que abarca múltiples formas de entender y trabajar con personas desde el nexo de la proximidad a las mismas».

26. Acerca del "tacto pedagógico" recomendamos la lectura del artículo de SANTOS GómEZ (2013b). 
2003, 42). Pero no solo el acto de educar requiere de este acompañamiento: la persona misma, desde un punto de vista antropológico, siente la necesidad de ser acompañada:

En el momento de nacer el hombre es un ser desvalido y desorientado; le faltan puntos de referencia fiables y, sobre todo, lenguajes adecuados para poder instalarse en el mundo, es decir, para humanizarse en el mismo acto de humanizar su entorno... Para llevar a cabo esa tarea, con ciertas garantías de éxito, necesitará de un conjunto de transmisiones que le faciliten la inserción en el trayecto vital que le corresponde, en cuyo recorrido deberá ser acogido en el seno de una comunidad y reconocido por ella (Duch, 2002, 11-12).

Si la relación ética de acompañar al otro y hacerse cargo de él no se produce, lo que tenemos es solo una mera transmisión de conocimiento, una simple instrucción, por este motivo, en educación el acompañamiento:

Impulsa al realismo y nos mete de lleno en las condiciones sociohistóricas en las que vive el educando. La realidad del sujeto no se reduce a sus características o rasgos personales; también su equipaje socio-cultural, sus condiciones de vida forman parte de "lo que es» cada individuo y no pueden permanecer al margen de los procesos educativos; también estas condiciones de vida deben estar afectadas si no se quiere reducir la educación a una actuación neutral fuera del tiempo y de la realidad (Ortega Ruiz, 2004, 10).

Por lo tanto, la preocupación ética se genera en el momento en el que «a uno [al maestro/a] le importa lo que le pasa al otro con las cosas que uno hace, o con las cosas que se están haciendo en la comunidad a la cual pertenece. Pero para que me importe lo que le pasa al otro tengo que verlo, y para verlo tengo que amarlo» (Romero Sánchez y Pérez Morales, 2013).

\subsection{El acompañamiento como acción concreta}

El acompañamiento no es ni un aspecto de mera educatividad, ni un simple constructo pedagógico al servicio de la educadibilidad (Denzin y Lincoln, 2013), ni un acto como mera "oportunidad de educar" (Nelson y Gordon-Larsen, 2006), es más bien todo lo anterior aglutinado en una acción concreta, y, como tal, se caracteriza en sus propios términos, que se deben concretar «desde la condición fundamentalmente del valor, la doble condición de agente y la doble consideración de conocimiento y acción para [desarrollar el fin último:] el objeto educación» (Touriñán, 2014, 23).

El acompañamiento y «el hacerse cargo del otro es una condición indispensable para que podamos hablar de educación. Y aquí está toda la razón de ser de la educación» (Ortega Ruiz, 2004, 10). Por eso, la relación del acompañamiento es básicamente una acción relacionada con el significado de la educación en cada ámbito fijado para intervenir. Todo esto es lo que convierte al acompañamiento en 
un ejercicio de autonomía comprometida y en una actividad responsable, "porque cuidamos para educar, es decir, para que cada educador, junto con el educando, genere en cada educando la relación educativa respecto de sí mismo, de tal manera que éste no sea solo actor, sino también autor de su propio proyecto de vida en lo que pueda, en cada ámbito de intervención creado» (Toriñán, 2014, 23).

La relación educativa del acompañamiento dispone de un sentido concreto a partir de las aptitudes personales de sus agentes. Cada acompañamiento es un acto de compromiso, de libertad, de decisión, en el que la práctica sentida de la acción concreta vincula valores, saberes y sentimientos de tal manera que, desde las cualidades personales de los agentes, la ejecución de la acción pueda ir creando el sentido específico de aquello que se quiere transmitir. De hecho, la relación ética de la que se hablaba en el anterior apartado del presente artículo no se fija en función de un deber absoluto aislado del tiempo y del espacio (Hernando, 2012), "ni es un factum de la razón pura práctica al margen de toda experiencia, como sostiene Kant, sino relación o respuesta diferente no al otro, sino del otro concreto, singular e histórico que siente, goza, padece y vive, aquí y ahora, como afirma Lévinas» (Ortega Ruiz, 2004, 10).

Por todo lo expuesto, la relación de acompañamiento, como sentido axiológico general, se tiene que poner al servicio de la "fuerza interior" del educando (Dubet, 2010) y debe buscar las vías para fijar la intersección entre el educando como sujeto social y la subjetividad que le es propia; por eso un maestro/a necesita de una formación basada en la madurez y la mejora personal. Esta formación debe encarar su preparación como profesional reflexivo como premisa necesaria pero insuficiente (Vanderberg, 2009).

Estar capacitado para ser alguien que no solo transmita conocimiento sino que acompañe al alumnado requiere la incorporación de elementos como la conciencia (Herrán, 1998; Torre, 2006). Todo ello puesto al servicio del objetivo último, conseguir que el educando se guíe desde su interior y se dote de pautas de actuación y habilidades basadas en unos principios (¿conocimiento, saber o competencias?... nos preguntábamos en la introducción de este artículo) que, simultáneamente, le proporcionen formas de adaptarse al mundo e instrumentos para analizarlo, para integrarse en la sociedad y para percibirse (con la necesaria lejanía que se requiera en cada caso).

Una nueva paideia que refuerce el acompañamiento educador-educando debe entender que toda socialización es una subjetivización (Renaut, 2004), y tiene que "Conciliar lo inconcebible, es decir, tener en cuenta que la subjetivación resulta de la socialización sin, con ello, ser una clonación totalmente social» (Dubet, 2010, 16). Porque, ¿qué es acompañar sino orientar nuestra identidad personal hacia la pretensión del conocimiento, querer saber más, categorizarlo todo o hacerlo problemático? ¿Qué es más que ponerse al lado de alguien para ayudarle a penetrar intelectualmente la realidad?, en definitiva. 


\section{REFLEXIONES FINALES}

A la Pedagogía le corresponde valorar cada área cultural como educación y conformarla como medio valorado, es decir, como ámbito de actuación (Torío López, 2015). Pero toda Pedagogía es consecuencia de una antropología y de una ética (Barrio Mestre, 2008), por eso no hay pedagogía sin ubicación ni proyecto educativo sólido que no deba tener en cuenta que «estamos viviendo la proliferación de múltiples propuestas acerca del diseño de sistemas educativos o sobre estrategias de enseñanza-aprendizaje en el aula sin que se observe la respuesta a una pregunta clave para cualquier educador: ¿por qué tipo de sociedad apostamos?, ¿qué modelo de persona es el que queremos formar? Interrogante básico, esencial, al que tiene que subordinarse cualquier proyecto educativo» (GuichotReina, 2015, 48).

En estas páginas hemos ubicado a la Pedagogía de la nueva Paideia en una intersección doblemente mediada: mediada con el cuerpo (en cuanto a ámbito de educación que construye) y mediada por el acompañamiento (en cuanto a necesidad de erigirse como elemento de intervención). Esta doble mediación habilita a la Pedagogía para desarrollar competencias adecuadas para la educación y para promover disposiciones básicas del educando en la relación educativa. Y todo sin olvidar que, en realidad, "no hay esencia de lo pedagógico, sino que es la propia experiencia -el acontecimiento- de una relación educativa lo que permite pensar qué significa ser un sujeto de la educación, qué significa lo pedagógico» (Bárcena, 2012, 54), es decir, que, en realidad, la finalidad de la Pedagogía es llegar a entender la extensión de la educación y los principios estructurales de su intervención. Por eso la Pedagogía permite generar cada ámbito de experiencia como un espacio general de educación y como un conjunto de competencias profesionales que preparan al educador para desarrollar su tarea docente.

Todo ello nos ha llevado a plantearnos el papel del cuerpo en la sociedad y cómo ésta determina diferentes modelos corporales, sobre todo, para permitir la concreción de lo que hemos llamado la pedagogía del cuerpo. Un cuerpo que "ha de tener la posibilidad de decir, de comunicar, de subjetivar, pero que no ha de pasar necesariamente por prácticas corporales que puedan presentar vivencias dolorosas del cuerpo» (Planella, 2005, 200). Asumir la dimensión educacional desde el cuerpo como impulso o instinto vital permite a la Pedagogía restituir un espacio a menudo silenciado desde los discursos pedagógicos de las últimas décadas.

El cuerpo forma parte de nuestra identidad personal y social, por eso todas las vivencias, sensaciones y percepciones las recibimos a través de él. En unas sociedades en las que el placer y el presente se han establecido como valores ideales, esto solo es alcanzable a través de nuestra identidad corpórea (Pericot, 2002). La imagen corporal es el resultado de una parte del sentido que le otorgamos a la existencia y de la forma en la que nuestra cultura mediatiza nuestra experiencia (Burkitt, 1999). La realidad corporal se ha convertido «en un símbolo expresivo del posicionamiento del individuo dentro de su sociedad. Por tanto, el valor social que adquiere el cuerpo implica el ser un medio de realización y desarrollo personal con 
el objetivo de alcanzar un ideal imaginario» (Fanjul, 2006, 317). Pero no hay ideal sin educación y no hay educación sin relación ética que (re)estructure y constituya la acción educativa como tal. La pedagogía del cuerpo y la actitud ética del acompañamiento relacionan mentalidad pedagógica y específica con acción. A través de las dos, el presente artículo ha ofrecido al conocimiento de la educación una mirada pedagógica especializada no solo como medio que propone condiciones de viabilidad de la acción, sino como marco de concreción que marca la posibilidad del hecho educativo mismo.

Todo lo expuesto se enmarca dentro del objetivo primario de la Pedagogía, ya que cualquier propuesta que pretenda ser válida se debe plantear desde unos parámetros "medios-fines» en los que los medios se adapten a la definición de educación que cada sociedad o cada contexto elija; porque cualquier medio no es solo un medio educativo: "Este es el punto clave de su sentido pedagógico, que se completa en la misma medida en que somos capaces de entender que los medios, al ser relativos a una finalidad, son medios respecto del sujeto que actúa" (Touriñán, 2014, 28), que actúa para desarrollar la finalidad de la acción, sea desde la pedagogía del cuerpo, sea a partir del compromiso ético canalizado a través del acompañamiento o sea desde cualquier otro sentido pedagógico que acredite un encaje entre el medio, el agente y la acción en cada situación concreta.

\section{REFERENCIAS BIBLIOGRÁFICAS}

Aguirre, A. (1993) Diccionario temático de antropología. Barcelona, Boixareu.

Ainscow, M.; Hopkins, D.; Soutwort, G. y Westy, M. (2001) Hacia escuelas eficaces. Manual para la formación de equipos docentes. Madrid, Narcea.

Alemany, C. (1996) El cuerpo pedagógico y sus implicaciones terapéuticas, en AlemanY, C. y García, V. (eds.) El cuerpo vivenciado y analizado. Bilbao, Desclée De Brouwer, 103-121.

Alfaro, R. (2014) Post-postmodernismo. Revista Reflexiones, 93 (2), 103-113.

AlONSO, L. (2001) El paradigma reinante y su Paideia. EDUCERE, 5, 13, 1-6.

AYALA, R. (2011) La esperanza pedagógica: una mirada fresca y profunda a la experiencia educativa desde el enfoque de Van Manen. Revista Española de Pedagogía, 69, 248, 101-118.

BÁrCENA, F. (2012) Una pedagogía de la presencia. Crítica filosófica de la impostura pedagógica. Teoría de la Educación, Revista Interuniversitaria, 24 (2), 25-57.

BÁrCENA, F. y MÈLICH, J. C. (2000) El aprendizaje simbólico del cuerpo. Revista Complutense de Educación, 11 (2), 59-81.

BÁrCENA, F. y MèLICH, J. C. (2003) La mirada excéntrica. Una educación desde la mirada de la víctima, en MARdones, J. M. y MATE, R. (eds.) La ética ante las víctimas. Barcelona, Anthropos, 195-218.

BARRIO MAestre, J. M. (2008) Sobre la llamada educación posmoderna. Revista Española de Pedagogía, 241, 527-540.

BERnASCONI, O. (2015) ¿Qué nos hace ser individuos? Por un enfoque post-humano, pragmático y relacional. Athenea Digital, 15 (2), 205-229. 
BrezinKa, W. (2002) Sobre las esperanzas del educador y la imperfección de la pedagogía. Revista Española de Pedagogía, 223, 399-413.

BurkitT, I. (1999) Bodies of thought. Embodiment, identity and modernity. London, Sage Ltd. CABrera, M. Á. (2005) La crisis de la modernidad y la renovación de los estudios históricos, en Ferraz, M. (ed.) Repensar la historia de la educación. Madrid, Biblioteca Nueva, 21-52.

Colom, F. (1999) Razones de identidad. Pluralismo cultural e integración política. Barcelona, Anthropos.

CuA, A. (1998) Moral vision and tradition. New York, American University Press.

De Miguel Díaz, M. (2015) Ideología y pedagogía empírica: cuestiones para un debate. RIE, 33 (2), 269-287.

Denzin, N. K. y Lincoln, Y. S. (coords.) (2013) Las estrategias de investigación cualitativa. Barcelona, Editorial Gedisa.

DerRick, C. (2011) Huid del escepticismo. Madrid, Ediciones Encuentro.

Dubet, F. (2010) Crisis de la transmisión y declive de la institución. Política y Sociedad, 47, 2, $15-25$.

Duch, Ll. (2002) Antropología de la vida cotidiana. Madrid, Trotta.

Echeverría, J. (2003) Cuerpo electrónico e identidad, en Hernández, D. (ed.) Arte, cuerpo, tecnología. Salamanca, Universidad de Salamanca, 13-29.

FAnjul PeYró, C. (2006) La apariencia y características físicas de los modelos publicitarios: códigos no verbales de la realidad en el discurso publicitario como factor de la influencia social mediática en la vigorexia masculina. Tesis doctoral. Universitat Jaume I de Castelló.

FERRAZ, M. (2012) De la pedagogía oficial a la pedagogía crítica. Un intento reflexivo por redefinir el perfil de su objeto de estudio. Revista Iberoamericana de Educación, 58 (4), 1-16. Consultado el 4 de marzo de 2016. http://www.rieoei.org/deloslectores/5145Ferraz. pdf.

Fontcuberta, J. (2011) Por un manifiesto posfotográfico. Lavanguardia.com. Consultado el 5 de abril de 2016. http://www.lavanguardia.com/cultura/20110511/54152218372/porun-manifiesto-posfotografico.html.

Freinet, C. (1972) L'educació moral i cívica. Barcelona, Laia.

Fullat, O. (1989) El cos educand, en Symposion Internacional de Filosofia de l'Educació. Bellaterra, UAB-UB, vol. II, Comunicacions, pp. 159-166.

Fullat, O. (2002) Le parole del corpo. Roma, Anicia.

Garavito, M. C. y YÁÑEZ, J. (2011) Las críticas al concepto de representación y las nuevas posibilidades de la investigación cognitiva desde las perspectivas de cognición situada y corporeizada, en YÁÑEZ, J. y PERDOMO, A. (eds.) Cognición corporizada y embodiment. Bogotá, Corporación Universitaria Minuto de Dios Uniminuto, 96-109.

García Carrasco, J. y García del Dujo, Á. (2001) Teoría de la educación II, Procesos primarios de formación del pensamiento y la acción. Salamanca, Ediciones de la Universidad de Salamanca.

GozÁlvez Pérez, V. (2010) Hacia una reconstrucción de la razón pedagógica. Teoría de la Educación. Revista Interuniversitaria, 22 (2), 19-42.

Guichot-Reina, V. (2015) El enfoque de las capacidades de Martha Nussbaum y sus consecuencias educativas: hacia una pedagogía socrática y pluralista. Teoría de la Educación. Revista Interuniversitaria, 27 (2), 45-70. 
Gumbrecht, H. (2010) Éloge de la présence. Ce qui échappe à la signification. París, Maren Stell.

Hernando Gómez-Esteban, J. (2012) Pedagogía de la metamorfosis. Magis, 4 (9), 725-740.

Herrán, A. (1998) La conciencia bumana. Hacia una educación transpersonal. Madrid, San Pablo.

Herrera, R. y CoDina, Ll. (2015) Redes sociales visuales: caracterización, componentes y posibilidades para el SEO de Sitios Intensivos en Contenidos. Cuadernos de Documentación Multimedia, 26, 3-24.

Huerta, R. y Alonso SANz, A. (2015) Educación artística y diversidad sexual. Valencia, Universitat de València.

KaAgan, S. y Headley, L. (2010) Bringing your learning community to life. A road map for sustainble school. Corwin, Thousand Oaks, CA.

Khun, T. S. (1978) La estructura de las revoluciones científicas. México, Fondo de Cultura Económica.

Kristal, E. (2002) Invisible Work. Borges and Translation. Nashville, Vanderbilt University-Press.

LAudo, X. (2011) La hipótesis de la pedagogía postmoderna: educación, verdad y relativismo. Teoría de la Educación. Revista Interuniversitaria, 23 (2), 2011, 45-68.

LAUDO, X. y PRATS, E. (2013) El lugar de la autonomía en la pedagogía y la educación postmodernas. Teoría de la Educación: Educación y Cultura en la Sociedad de la Información, 14 (1), 248-262.

Le Breton, D. (2000) El cuerpo y la educación. Revista Complutense de Educación, 11 (2), 35-42.

Le Breton, D. (2002) Signes d'identité. Tatouages, piercings et autres marques corporelles. París, Metailié.

Leithwood, K.; Mascall, B. y Strauss, T. (2009) Distributed leadership according to the evidence. New York, Routledge.

López Gallego, M. (2013) Bildungsroman. Historias para crecer. Tejuelo, 18, 62-75.

López Herrerías, J. A. (2010) ¿Qué "yo" es valioso para el mundo de hoy? Teoría de la Educación. Revista Interuniversitaria, 22 (1), 65-90.

March, M. X.; Orte, C. y BAllester, Ll. (2016) La pedagogía social en España: de la reconstrucción académica y profesional a la incerteza científica y social. Pedagogía Social, Revista Interuniversitaria, 27, 45-82.

Marchart, O. (2009) El pensamiento político posfundacional. Buenos Aires, Fondo de Cultura Económica.

Mattei, M. (2014) El divismo en tiempos de Instagram. Cuadernos de Información y Comunicación, 20, 95-107.

McCourT, F. (2010) El profesor. Madrid, Maeva Ediciones.

MÉLICH, J. C. (2003) La sabiduría de lo incierto. Educar, 31, 33-45.

MÉLich, J. C. (2008) Antropología narrativa y educación. Teoría de la Educación. Revista Interuniversitaria, 20, 101-124.

Mondzain, M. J. (2007) Homo spectator. París, Bayard.

Nassif, R. (1977) Pedagogía general. Madrid, Cincel.

Nussbaum, M. C. (2012) Crear capacidades. Propuestas para el desarrollo humano. Barcelona, Paidós.

Nelson, M. C. y Gordon-Larsen, P. (2006) Phisycal activity and sedentary behavior patterns are associated with selected adolescent health risk behaviors. Pediatrics, 117 (4), 1281-1290. 
Nubiola, J. (2001) Pragmatismos y relativismo. C. S. Pierce y R. Rorty. Themata. Revista de Filosofía, 27, 49-57.

OrLan, F. (2002) Virtuel et réel, en FinTz, C. (dir.) Du corps virtuel... à la réalité des corps, vol. II. París: L'Harmattan, 203-213.

Ortega Ruiz, P. (2004) La Educación Moral como Pedagogía de la Alteridad. Revista Española de Pedagogía, 227, 5-30.

Pagano, R. (2001) Educazione e interpretazione. Linee di una pedagogia ermeneutica. Brescia, La Scuola.

Pallarès Piquer, M. (2014) El legado de Paulo Freire en la escuela de hoy: de la alfabetización crítica a la alfabetización en medios de comunicación. Teoría de la Educación. Revista Interuniversitaria, 26 (1), 59-76.

Pericot, J. (2002) Mostrar para decir. La imagen en contexto. Barcelona, Aldea Global.

PÉrez DAZA, J. (2015) Fotografía en tiempos de darwinismo tecnológico. Aularia, 1, 9-14.

PÉREZ LunA, E. (2003) La pedagogía que vendrá: Más allá de la cultura escolar positivista. Utopía y Praxis Latinoamericana. Revista Internacional de Filosofía Iberoamericana y Teoría Social, 23, 87-95.

Planella, J. (2005) Pedagogía y hermenéutica del cuerpo simbólico. Revista de Educación, $336,189-201$.

Planella, J. (2006) Cuerpo, cultura y educación. Bilbao, Desclée de Brouwer.

Planella, J. (2013) Pedagogía Social y diversidad funcional: de la rehabilitación al acompañamiento. Educatio siglo XXI: Revista de la Facultad de Educación, 31 (2), 113-128.

Planella, J. (2016) Pedagogía de lo sensible. Subjetividades encarnadas en la escuela educación corporal, en AA. VV. Escola e professor(a): identidades em risco? Santa Cruz do Sul. Rio, Edições UnISC.

Porter, R. (1993) Historia del cuerpo, en Burker, P. (coord.) Formas de hacer historia. Madrid, Alianza, 255-286.

Raimondo, N.; Reviglio, M. C. y Divani, R. (2015) Esfera pública y redes sociales en Internet: ¿Qué es lo nuevo en Facebook? Revista Mediterránea de Comunicación, 7 (1), 1-19.

RANCIÈRE, J. (2010) El espectador emancipado. Castellón, Ellago Ediciones.

Renaut, A. (2004) La fin de l'autorité. París, Puf.

Rombach, H. (2004) El hombre humanizado. Antropología estructural. Barcelona, Herder.

Romero Pérez, C. y Pereira, C. (2011) El enfoque positivo de la educación: aportaciones al desarrollo humano. Teoria de la Educación. Revista Interuniversitaria, 23 (2), 69-89.

Romero Sánchez, E. y Pérez Morales, C. (2013) Aproximación al concepto de responsabilidad en Lévinas: implicaciones educativas. Bordón, 64 (4), 99-110.

SÁNCHEZ MADRID, N. (2011) Educación, Cultura y Estado-nación en Hannah Arendt y Theodor Adorno. Dos lecturas de los orígenes del totalitarismo. Ontology Studies, 11, 65-85.

Santos Gómez, M. (2013a) Análisis de las bases filosóficas de las aportaciones de Pierre Bourdieu a la Teoría de la Educación. Revista Complutense de Educación, 24 (2), 381-396.

SANTOS GÓmEZ, M. (2013b) Educación, símbolo, tacto. Más allá del modelo instrumental en la pedagogía. $A R B O R, 189,1-9$.

SHIRKY, C. (2011) A cultura da participação: critavidade e generosidade num mundo conectado. Rio de Janeiro, Zahar.

Synnolt, A. (1991) The Body Social Symbolism. Self and Society. London, Routledge.

TEDDlie, C. y REYNOLDS, D. (2000) The international handbook of school effectiveness research. London, Falmer Press. 
Thiebaut, C. (1998) Vindicación del ciudadano. Un sujeto reflexivo en una sociedad compleja. Barcelona, Paidós.

Torío López, S. (2015) Pedagogía mesoaxiológica y concepto de educación. Revista Complutense de Educación, 3, 802-804.

TORRE, S. (2006) Creatividad en educación, en Torre, S. y Violant, V. (coords.) Comprender y evaluar la creatividad, vol. I. Málaga, Aljibe, 123-154.

TouriÑán, J. M. (2014) ¿Dónde está la educación? Definir retos y comprender estrategias. A propósito de un libro de 2014. Revista de Investigación en Educación, 12 (1), 6-31.

VAN MANEN, M. (1998) El tacto en la enseñanza. El significado de la sensibilidad pedagógica. Barcelona, Paidós.

VAN MANEn, M. (2003) Investigación educativa y experiencia vivida. Barcelona, Idea Books.

VANDENBERG, D. (2009) Critical thinking about truth in teaching: The epistemic ethos. Educational Philosophy and Theory, 41 (2), 155-165.

VÁzQuez RAmos, D. (2011) La virtud de la studiositas y el conocimiento. Un estudio desde Santo Tomás de Aquino. Cuadernos de Filosofía. Excerpta e dissertationibus in philosophia, 21, 93-198.

Veletsianos, G. (2010) A definition of emerging technologies for education, en Veletsianos, G. (ed.) Emerging technologies in distance education. Athabasca, CA, Athabasca University Press, 3-22.

Vilanou, C. (2000) ¿Es posible una Bildung hermenéutica? Perspectiva Educacional, 35-36, 25-43.

Vilanou, C. (2001) Imágenes del cuerpo humano. Apunts, 63, 94-104.

Vilanou, C. (2003) Proyecto docente e investigador. Concurs de Catedràtic. Departament de Teoria i Història de l'Educació. Facultat de Pedagogia. Universitat de Barcelona.

Wenger, E (2001) Comunidades de práctica. Aprendizaje, significado e identidad. Barcelona, Paidós. 